\title{
Medical Students Perceptions Over Their Motivations and Competencies to Volunteer in COVID-19 Pandemic - An Opportunity to Develop Leadership Skills During Medical Training
}

Marina Alves Martins Siqueira ( $\square$ marina.siqueira@fm.usp.br)

Universidade de Sao Paulo

Matheus Belloni Torsani

Universidade de Sao Paulo

Gustavo Rosa Gameiro

Universidade de Sao Paulo

Lucas Albuquerque Chinelatto

Universidade de Sao Paulo

Bruna Chacon Mikahil

Universidade de Sao Paulo

Patricia Zen Tempski

Universidade de Sao Paulo

Milton A. Martins

Universidade de Sao Paulo

\section{Research Article}

Keywords: Volunteering, Medical Students, COVID-19, Motivation, Leadership, Curriculum

Posted Date: October 5th, 2021

DOI: https://doi.org/10.21203/rs.3.rs-882146/v1

License: @ (i) This work is licensed under a Creative Commons Attribution 4.0 International License.

Read Full License 


\section{Abstract}

\section{Background}

Considering evidence on competency-based curriculum and the benefits of volunteering, this study highlights new ideas to improve medical education during the COVID-19 pandemic. We investigated the motivations and perceptions on competencies developed as leadership and management skills in medical students who joined COVID-19 Volunteering Program in a brazilian medical school.

\section{Methods}

We performed a cross-sectional, quantitative and qualitative study involving medical students from the University of Sao Paulo (USP)/Brazil. They were invited to participate in an institutional Volunteering Program during the pandemic, and filled online application forms, including sociodemographic fields and two open-ended questions about motivation to volunteer and perceptions on their own competencies. At the end of the Program, students who were involved in management-related activities were also invited to participate in focus group interviews to track their perceptions about volunteering in this area. Data were submitted to descriptive and content analysis methods. All participants provided informed consent through electronic signature.

\section{Results}

286 medical students have subscribed to the Volunteering Program: 171 (60\%) were men, 152 (53\%) were enrolled in 5th year and 158 (55\%) were $23-25$ years old. One-hundred and twelve (44\%) students volunteered motivated by altruistic reasons, $95(37 \%)$ reported duty and $47(19 \%)$ prioritized academic interests. Concerning CanMEDS competencies, 91 (36\%) students' responses matched with the Scholar component, followed by 51 (20\%) with Collaborator, 49 (20\%) with Professional, 32 (13\%) with Communicator, 17 (7\%) with Leader and 11 (4\%) with Health Advocate.

In focus groups, students reported the importance of management and leadership skills as a curricular component, motivations to volunteer, the acquired skills from volunteering in management and leadership-related activities, highlighting the development of resilient attitude.

\section{Conclusions}

Students who participated in the FMUSP Volunteering Program reported being motivated to help others (altruistic reasons) and to serve society as future health professionals (duty). Knowledge and workrelated competencies prevailed over leadership or soft skills, emphasizing the importance of including such activities in curriculum. Participating in management-related activities could help develop a more resilient attitude towards medical training.

\section{Take home messages}


Volunteering programs offer students opportunities to develop essential competencies for the future health professional. Thus, we should think about including such activities in curricular structure.

\section{Background}

The confirmation of the COVID-19 pandemic by the World Health Organization on March 11, 2020 has led to the adoption of plenty of measures to decrease the virus spreading. By the time this article was submitted, according to the World Health Organization (WHO) Coronavirus Dashboard, there have been 220.563.227 confirmed cases of COVID-19, including 4.565.483 deaths, reported to WHO. Also, a total of 5.289.724.918 vaccine doses have been administered [1]. Social distancing directly affected the educational system, since, in the first moment, all academic activities had to be suspended [2-3]. Health systems, on the other hand, faced a burden of patients and imminent resource scarcity [4-8], which required a massive reorganization of services, logistics management and staff.

In Sao Paulo/Brazil, the State Council of Universities determined the suspension of both on-campus classes and extracurricular activities in March, 2020. The exceptions were health sciences internships [9]. Consequently, faculty had to rapidly reshape activities to the virtual environment, as well as adjust internship rotations [10]. At the School of Medicine of the University of Sao Paulo, medical students were invited to participate in a Volunteer Programme and support health and educational services linked to the University. Under the support from the University Educational Dean, students could opt to volunteer to activities involving health assistance, research, education and hospital administration, according to the required skills and responsibilities. Time spent on voluntary activities should not pose a hindrance to the curricular online activities [3].

Volunteering is defined as the dedication of an amount of time to activities without any expectations of compensation. Although, there are occasional collateral benefits to those who take part in voluntary services, ranging from physical to psychological impacts [11]. According to previous studies, involving undergraduate students, development of leadership, self-confidence, critical thinking and conflict mediation skills are immediate benefits from volunteering. Moreover, it is associated with higher commitment to community and social values [12-15]. In the long term, students who volunteer are more likely to perform voluntary activities after graduation, besides being more tolerant and open-minded people [13].

Concerning motivations to volunteer, this is mainly an individual decision however one cannot dismiss the impact of societal forces, to some degree. A study involving students from universities of six countries - Belgium, Japan, Canada, United States, China and Finland - showed that to younger, economically-active individuals, willing to volunteer are mostly associated with an opportunity to acquiring skills or improving job opportunities, while older, retired volunteers are influenced to a greater proportion by altruistic reasons [12].

Another relevant factor is students' motivation for choosing medical career: according to a literature review, students are motivated mainly by scientific and financial interests, followed by humanistic 
reasons [14].

In order to guarantee excellence standards for medical education and health assistance, prepared physicians who fulfil societal needs, and reflect values of the next generation of health professionals, the Canadian Medical Education Directives for Specialits (CanMEDS) from the Royal College of Physicians and Surgeons of Canada proposed the Physician Competency Framework [16]. It is known that competency-based curricula are ultimately necessary for the 21 st century physicians, as it prioritizes accountability, integration with the health system, learning outcomes and promotes student-centered learning [17-19]. Having this considered, subjects involving the development of leadership skills, such as health systems politics and health services administration should be given more attention in the medical core curriculum worldwide.

The aim of the present study is to investigate competencies and motivations of undergraduate students enrolled in a Volunteer Programme during the COVID-19 pandemic and provide data to afford the inclusion of activities involving health-administrative and leadership skills in the curricular structure.

\section{Methods}

\section{Study design}

We performed a cross-sectional, quantitative and qualitative study, involving medical students enrolled in 4th, 5th and 6th years of medical programme, who have subscribed in the Volunteer Programme at the University of Sao Paulo (USP), Brazil. Out of that previously described population, a convenience sample was selected to undergo focus group interviews so as to explore how the volunteering experience was perceived by the students. Focus group interviews consist on an excellent method to understand, in a qualitative study context, not only the general perception of the subjects of any subject, but also help the researchers to identify one's perception, thinkings, opinions, feelings and non-verbal expressions that go way beyond the traditional quantitative methods $[20,21]$.

\section{Local structure of the Brazilian medical programme and participants}

In Brazil, a medical degree is obtained in a 6-year undergraduate programme, which is traditionally divided into three periods: basic sciences (1st and 2nd years), clinical sciences (3rd and 4th years) and clerkships (5th and 6th years) [22]. Our Volunteer Programme included students from 4th, 5th and 6th years $(n=525)$, who already had enough clinical experience at this program stage.

\section{Data collection}


With Education Dean's consent, we obtained data from the Volunteer Programme subscription form. Data were properly anonymised and informed consent was obtained at the time of original data collection [23]. The research ethics committee of the School of Medicine of the University of Sao Paulo approved this study.

Before focus group interviews, participants also provided informed consent through electronic signature.

\section{Descriptive statistics}

The variables assessed were gender, age, year of medical programme, pre-existent diseases included in risk groups for COVID-19, type of transport used, and interest in six different areas of voluntary activities. We used descriptive statistics to analyse demographic data. It was performed using SPSS Statistics for Windows, Version 22.0 (released 2013, IBM Corp, Armonk, NY).

\section{Qualitative analysis: open-ended questions and focus group interviews}

We performed qualitative analysis based on two open-ended questions attached to the Volunteer Programme subscription form:

(1) What motivates you to volunteer during the COVID-19 pandemic?

(2) Which of your skills and attitudes do you think can contribute to the volunteer programme?

Focus group interviews included the following guiding questions:

(1) Which management-related activities have you performed as a volunteer during the COVID-19 pandemic?

(2) How would you describe the approach to health-administrative and leadership skills during medical training? Is there any curricular activity involving this subject?

(3) What motivated you to choose volunteering to health-administrative activities during the COVID-19 pandemic?

(4) What do you think was/were the most important knowledge or skills you have learned with this experience?

Two focus groups were conducted with students who participated in management-related activities as part of the Volunteering Program. Each group included 3 and 4 participants, respectively, both lasting approximately 1 hour. Each student participated only once. The interviews were guided by the same moderator with experience in the field. One more researcher was also present to take notes for further 
discussion. Participants were provided with information about the study objectives, methodology and confidentiality at the beginning of all sessions. Questions were open-ended, carefully thought to promote interaction, discussion, reflection and to explore participants' perspectives and criticism about the volunteering. All interviews were performed through online conferences, recorded with participants' consent and transcribed for posterior analysis.

We adopted Content Analysis Methods [24-30] for the analysis of responses to the open-ended questions and focus group interviews. The researchers started with a free reading of the transcribed text, without the intention of categorization. During the second reading, they proceeded to the categorization of emerging themes and derived issues separately. Finally, each researcher's products were paired similarities in meaning and were discussed with the research group. The results were divided into analytical categories and examples. Some examples were selected to illustrate each of the elected categories and were translated into English.

\section{CanMEDS 2015 Physician Competency Framework}

We have chosen the Canadian Medical Education Directives for Specialits (CanMEDS) from Royal College of Physicians and Surgeons of Canada [16] to guide the analysis and to categorize the students' answers about their competencies. According to this framework, competencies for future physicians can be described as:

Communicator: forms relationships with patients and their families, that facilitate gathering and sharing of information. The professional must adopt active listening techniques and an empathic, patient-centred approach. He/she must share decisions and guarantee patients privacy and information confidentiality;

Collaborator: works effectively with other health professionals, providing safe, high-quality, patientcentred care;

Leader: contributes to a vision of high-quality health care system, compromised with excellent patient care as clinician, administrator, scholar or teacher;

Health advocate: employs his/her expertise and influence on behalf of the population needs, supporting the mobilization of resources to effective change;

Scholar: demonstrates lifelong commitment to excellence in practice, through continuous learning. Teaches and supervises new learners, evaluate and produce scientific evidence;

Professional: commits to their patients and population health and well-being, through ethical practice, accountability and maintenance of personal health.

\section{Results}




\section{Volunteers' socio demographic profile}

Of 525 students enrolled in 4th, 5th and 6 h years of medical training, $286(54,4 \%)$ subscribed in our COVID-19 Volunteer Programme. Thirty-five answers (12,2\%) accounted for missing values, once we identified blank fields in the subscription form or could not include them in any category for qualitative analysis.

Regarding sample characteristics, 171 (60\%) were men, $152(53 \%)$ were enrolled in 5th grade of medical programme, 158 (55\%) were 23 to 25 years old, and 111 (39\%) reported they would walk to volunteer sites (Table 1).

The COVID-19 Volunteer Programme subscription form allowed students to choose between six areas of greater interest: (1) COVID-19 patients clinical assistance; (2) Non-COVID-19 clinical assistance; (3) epidemiological surveillance; (4) clinical research; (5) support to online educational activities; (6) hospital administration (Table 2).

\section{Open-ended questions: motivation to volunteer}

Concerning students' motivations to volunteer, some themes emerged from their responses, as follows (Table 3):

\section{(1) Altruistic reasons}

Since COVID-19 pandemic started, medical students promptly offered their help as volunteers. They reported a great willingness to contribute to decrease the harm caused by the disease, from assisting patients to helping professional colleagues, without expectations of any rewards.

"I believe we are going through an unique and delicate moment of great difficulties. I would like to help and try to minimize the impacts of the COVID-19 pandemic, concerning patients and health care professionals".

"What motivates me is to help people who are going through great suffering. I would like to help my health care colleagues who are working and exposing themselves to take care of all the patients. I am willing to do whatever work is needed".

Some of them also left their homes in order to get closer to the hospital and protect their beloved ones from infection, in case they were recruited to help in the health services.

"I decided to volunteer for the same reasons that I have chosen the medical career. I am living far of my parents, who are from risk groups for COVID-19 infection, what makes me more available to help. I wish I 
could contribute, making health assistance as efficient as possible, and diminishing health professionals wordload. Regarding my limitations as a student, I am willing to help whenever it is necessary".

\section{(2) Duty}

Another group of students have reported they felt socially responsible for helping in the pandemic, as future health professionals. Also, being enrolled in a medical course at a public university was strongly associated with this sense of debt towards society.

"Since I study in a public university, I believe I have a social obligation in the face of such a critical moment as COVID-19 pandemic".

"The critical circumstances imposed by COVID-19 pandemic and the challenges it brings for our health system makes me feel responsible for helping to fight against the disease".

"I believe medical students have a great pledge to assist the population as future doctors, graduating at a public university. (...) I also volunteered as a way to confront the feeling of powerlessness I believe a lot of my colleagues are facing too".

\section{(2) Academic interests}

Some students have reported being attracted by the opportunity to actively join the efforts to control the pandemic as volunteers, since they identified this as an unique learning experience. They were interested in learning about clinical aspects of the infection and understanding the health system organization in face of this peculiar situation.

"We are under a state of emergency - a pandemic with such proportions the world had not faced in a hundred years. I am proud of my University and Hospital for being an example for the rest of Brazil. I think the learning experience we can take out of it is huge. Medicine is the career I chose for my life and helping is a way of thanking all my colleagues currently working in the frontline against COVID-19".

"I would like to help in the efforts against the pandemic and to put all the knowledge acquired during undergraduation into service of the population. I am also interested in learning how to manage COVID-19 cases and how the health system is organizing in the midst of this unprecedented global shift".

Most of the responses referred to altruistic reasons to volunteer (44\%), followed by duty (37\%) and academic interests (19\%) (Figure 1).

\section{Open-ended questions: volunteers perceptions on their competencies}


Regarding students' perceptions on their own skills, we performed content analysis of responses, based on the six competencies framework from Royal College of Physicians and Surgeons of Canada (CanMEDS, 2015) (Table 4):

\section{(1) Communicator}

Students who have reported abilities associated with establishing relationships and providing information and orientation to patients and families were categorized as communicators, as their outstanding competency, as in the following example:

"I am communicative, very easy-going and helpful. I wish I could participate in activities involving patient orientation about COVID-19 or assisting inpatients at wards (COVID-19 or not). I'd really enjoy working in those areas".

\section{(2) Collaborator}

Students who have mentioned collaborative skills defined themselves as proactive and helpful. They were willing to learn new things in order to contribute to the work team and improve patient care.

"I am willing to work wherever I can be helpful! I am committed to learn any necessary skill and give all I can in order to help my colleagues and patients throughout this pandemic. One could say that I am a committed, organized and hardworking person. I am also willing to develop new competencies to help in any kind of volunteer activity".

\section{(3) Leader}

Leadership could be identified in students who reported experiences with student representation on university councils or were enrolled in extracurricular activities, generally performing administrative tasks. We observed that this group also was predominantly motivated to volunteer due to a social duty awareness.

"I believe that I am able to lead and organize people in a team, which might be useful in many contexts. I have worked in a research project during an exchange program for one semester and I have developed some ability in this field also. I have been class representative for many semesters and therefore I have learned a little about students' demands related to online education, which could be useful to volunteer activities. I am only in the 4th year, so although my medical abilities are limited I am very interested in medicine and a keen learner".

\section{(4) Health advocate}


The health advocate profile was the least common among students. This group of students showed higher awareness about the importance of public measures to contain the spreading of COVID-19. Students reported:

"I am a communicative, collaborative, resilient person. I also like to work in a team. I would like to perform activities involving patient assistance or epidemiological data assessment. I think it is very important to help the population to raise awareness about COVID-19 pandemic, in order to control it".

\section{(5) Scholar}

A considerable number of students described themselves as academically prepared to take part in voluntary activities. They have mentioned previous knowledge and academic experiences as potential contributors to the Volunteer Programme.

"I have some knowledge from previous experience in non-COVID internships (Neonatology and Obstetrics) and a great interest in Internal Medicine and clinical reasoning, focused on treating COVID patients. I also have previous experience in scientific research (Harvard Exchange Program)".

\section{(6) Professional}

Students who defined themselves as reliable and ethical called attention by their professional competency. They have commonly reported commitment and seriousness as their main qualities, as follows:

"I am very helpful and committed to tasks when they are attributed to me. I am also very willing to learn new things and work in teams. I also believe that my attitude of taking things seriously and not panicking in face of negative outcomes, always helping my colleagues on their needs and challenges, are good characteristics to volunteer services".

Regarding quantification of responses, most students defined themselves as Scholars (36\%), followed by Professionals (20\%), Collaborators (20\%), Communicators (13\%), Leaders $(7 \%)$ and Health Advocates (4\%) (Figure 2).

\section{Focus group interviews: perceptions on management- related activities and development of leadership skills during graduation}

The focus group interviews included seven students who participated in health-administrative activities as part of the Volunteering Program. Their discussion was organized in 4 categories, and divided into 15 issues (Table 5). 


\section{(1) Activities performed as volunteers}

Students started the discussion by retrieving some experiences they had during volunteering. They highlighted activities such as remote monitoring and providing comfort to patients with confirmed diagnosis of COVID-19, which was a grateful experience. They have also reported managing a great amount of epidemiological data, which required skills such as teamwork, leadership and organization, as well as technical knowledge to critically analyze evidence about the COVID-19 pandemic. Participating in management-related activities have contributed to the development of a sense of responsibility, autonomy and innovation for students. Some examples of their speech were:

\section{(a) Healthcare-related activities}

"Many times, people who lived alone were scared, in the beginning of the pandemic, (...) they didn't know how their disease would progress (...) so, we called and we kept calling and sometimes from one day to another we recognized the voices (...) it was gratifying to do this follow up."

\section{(b) Leadership and innovation}

"I thought that it was [an] enriching [experience] because we worked with different people. Furthermore, we managed to work in a group to organize that huge amount of data and try to come up with some productive thing from that."

"I think [writing the institutional COVID-19 protocol] was something very authoral, as it was our idea. [The supervisors] were just guiding us. We had weekly meetings with them and some among ourselves. With that we decided how to write. We were divided and each one was writing a topic."

"What I found interesting was precisely [the fact] that neither we, nor them, none of us knew how to write this document. So everything was being built and [the supervisors] experience as managers helped us a lot to see what would be feasible and applicable in our reality."

"In fact, besides thinking about new ideas, we have adapted many things to the reality of the University of São Paulo. Because whether we wanted to or not, we discussed it a lot (...) And we couldn't find almost anything in other documents. Because USP has infinite realities. And we were in a big discussion: "How are we going to do this? Are we going to list everything?" So I think it was a great adaptation to our reality and it was really cool."

\section{(c) Research}

"It was a secure experience because we talked by phone, we received the orientations, we were prepared (...) we could communicate with people and learn from them how the symptomatology presented (...) I 
think that in this aspect we learned and discovered the disease."

"Firstly, we conducted research to develop the basis of the [USP COVID-19] protocol (...) knowing the evidence about social distancing, masks, PPIs, tests and trying to bring that to USP reality (...)."

\section{(2) Importance of management and leadership skills as a curricular component}

It was unanimous among students the ultimate need for including management and leadership in the medical curriculum. But they differ on the focus of teaching. Some of them consider these skills important mainly for private practicing in the future, but another group thinks that learning about publichealth administration is fundamental and, coming from a public school, this is quite a moral obligation. They would also like to discuss more about political and administrative issues that affect their academic experience as future health professionals, as a curricular activity. They have reported:

\section{(a) Private practicing}

"(...) you will occasionally have some management position in your private practice, in a hospital, in the health system, public, private (...) even in the micro, if you have a small room as your office, you already have to do some management of supplies, human resources, logistics... and, in that sense, we have zero knowledge."

"In a hospital, public or private, [having management skills] is very important and it ends up that, in Brazil, these positions used to be occupied by non-health professionals. However, we see that it is starting to change recently, [as many doctors are starting to get trained for this]. I really don't know if there is any medical school that includes [management or leadership skills] in the curriculum, but I think it is very necessary. And it is also important for private practicing in the future. We leave college without knowing how to manage our own clinic."

\section{(b) Public health administration}

"It is interesting to see in the macro view, you know? How the hospital was in that moment, we had a good dimension of how the hospital reduced in the worst time of the pandemic (...) it was very interesting to see from that point of view."

"In fact there should be room for [management and leadership] at graduation, especially in terms of public health. Because our university is public and we will work for most of our graduation - in fact, in full - at SUS." 


\section{(c) Reflection on action}

"I think that our teaching hospitals, for example, would be a good opportunity for including management in the undergraduate program. We went through several crises, and are still going through some of them, in terms of hiring issues and lack of personnel, excessive demand, participation of private initiatives and so on. There are so many contradictions in terms of management and in terms of public health, but I feel that our teachers take very little responsibility for discussing this with us."

\section{(3) Motivation to volunteer}

The sample of students invited to participate in focus group interviews showed very similar motivations to volunteer to the universe of volunteers. They reported altruistic reasons, academic interests and exploring new opportunities. Some examples were:

\section{(a) Exploring new opportunities}

"I have chosen volunteering in management because I thought it could be an opportunity to learn something new that I would not learn during graduation. Although I felt unprepared by that time, I think it was a great experience."

"(...) At the beginning, I was afraid of the administrative field, so much that it was not my first option for volunteering. I have never felt capable, maybe because during graduation we do not have so many experiences like that. (...) Despite that, the volunteering program was a great opportunity to take the risk and overcome fear."

\section{(b) Altruistic reasons}

"(...) The idea of contributing in some way to help in this moment of pandemic was of interest to me. As I was far away and that could be made (...) I wanted to help (...)"

"I believe that we, as future doctors, need to develop a sense of leadership and responsibility, and the fact that I study in a public university makes me feel like I have a moral obligation to return what was invested in me to society."

\section{(c) Academic interests}

"I applied for almost every project at Volunteering Program, because I did not wanted to stay at home during the pandemic. (...) I find it very difficult to learn by reading books or attending theoretical classes. I need to apply things. And that is the way I learn best." 


\section{(4) Acquired skills from volunteering in management and leadership-related activities}

This session also resulted in similar issues, compared to all volunteers responses (see "Open-ended questions: volunteers perceptions on their competencies"), highlighting some CanMEDS competencies such as the Collaborator, the Communicator, Scholar and Professional. However, a new issue came up, which was Resilience. Students reported developing an ability to cope with frustrating situations, such as characteristic delays on referrals in the health system, as they could empathize with professionals and watch closely the work involved in managing such issues. Here are some examples to better understand this process:

\section{(a) Resilience}

"From the moment we jumped into this management thing, we learned to deal with the frustration of an uncontrolled environment, not controlled by ourselves or our team."

\section{(b) Collaborator}

"(...) because we are used to only criticize the public administration and the way the things are done especially in critical situations that nobody has answers (...) so understand and live the limitations (...) made people sympathize with other that are in that position, being more comprehensive with the limitations (...)."

\section{(c) Communicator}

"I think that what I will carry with me, what most touched me in this voluntary process in the vigilance area was the importance of communication."

\section{(d) Professional}

“(...) (it) showed the necessity of organization, management of people, like the colleagues that were also participating in the vigilance (...) It was a great work that we did together, we felt what were the difficulties and built solutions to those challenges."

\section{(e) Scholar}

"I think there was some technical learning involved, for example: I had never performed a review of literature before; and all the work of choosing and reading articles, to create a large group of references." 


\section{Discussion}

Students who volunteered in FMUSP Volunteering Program presented with a high prevalence of scholar, professional and collaborator self-perceived profiles. Altruistic reasons and duty prevailed as motifs to volunteering.

More than half of volunteers were from 5th year of the medical programme. This was probably due to the fact that this group was the only one that did not have any curricular activity since the quarantine was established. The 4th years were enrolled in online classes and the 6th year students had on-campus activities maintained.

Concerning motivation to volunteer, altruistic reasons can be associated with the acute crisis imposed on public welfare services [12] in the context of the pandemic, that victimized millions of people and defied health systems globally $[1,10]$.

According to literature, interests in volunteering may be also related with the construction of professional identity. Most of the students have chosen to work with patient care, what can be considered to be an effort to develop their identity as doctors through "apprenticeship" [31]. Besides, it might represent an opportunity for students to develop a sense of peer unity as medical students and within the medical school [31-32].

Having the opportunity to participate in actions against the pandemic, while others must stay at home isolating themselves, gives the student a sense of purpose and responsibility, which may also increase their interest in volunteering throughout this period.

It is important to notice that students must develop a pool of competencies throughout medical training, and identifying their perceptions about their own skills is valuable data for faculty to reinforce curricular and institutional strengths and mitigate deficits. Students have mostly reported knowledge and workrelated competencies rather than the ones associated with leadership or soft skills. This data converges to previous studies which describe career choice of brazilian medical students is associated with intellectual curiosity and professional autonomy [33]. A traditional curricular structure seems likewise to have great influence in these results, as competencies emphasizing cognitive processes are still expected to prevail [17]. Furthermore, we cannot disregard the hidden curriculum and role modeling influence, considering the academic and research tradition of our institution and faculty [34].

Students' initiatives of volunteering in the COVID-19 pandemic were not restricted to Brazil. In many countries, like the United States, United Kingdom and Portugal, students and faculty have organized similar programmes [35-37]. We believe that it will persist after pandemic, offering students notable professional and personal benefits, as previously mentioned [11-13, 15]. 


\section{New perspectives: incorporating management and leadership skills in medical curriculum}

In view of the positive results that we observed within the volunteer project in management at the Hospital Universitário, a proposal was made to reformulate the grade of the medical course in the 6th year. From the experience reported by the students, it was understood to be important to have an internship in Hospital Management, so that the student's training experience was more complete.

Then, an internship proposal was prepared, which begins with a theoretical deepening on the theme, especially focused on the area of regulation of health services, followed by practical training, in the medical course workshop, for skills development in this area. Finally, along the longitudinal stages in the $\mathrm{HU}$, students will be distributed on specific emergency coordination shifts, together with hospital managers, in order to develop and evaluate the necessary attitudes for health management competence.

In addition to the elaboration of activities, a framework was also designed to assess students that reaches the four levels of Kirkpatrick's taxonomy: assessment of satisfaction through an assessment form by students after theoretical-practical training; learning assessment with theoretical test on hospital management and regulation; behavioral assessment through observation by supervisors during practical activity; and, finally, impact assessment, analyzing the performance metrics in regulation performed by students.

\section{Conclusion}

The majority of students reported being motivated to volunteer in the COVID-19 pandemic, to help others (altruistic reasons) and to serve society as future health professionals (duty). These results were expected, considering the impact of the pandemic to the health system and society all over the world. Concerning volunteers competencies, knowledge and work-related ones prevailed over leadership or soft skills. This emphasizes the importance of developing a more competency-based curriculum and including such activities in core curriculum. Participating in management-related activities could help develop a more resilient attitude towards medical training.

\section{Abbreviations}

USP University of São Paulo

FMUSP School of Medicine of the University of São Paulo

CanMEDS Canadian Medical Education Directives for Specialits

\section{Declarations}

\section{Ethics approval and consent to participate:}


This study received approval from the Research Ethics Committee of the University of São Paulo. Number of approval protocols: 4.190 .524

\section{Availability of data and materials:}

The datasets used and/or analysed during the current study are available from the corresponding author upon reasonable request.

\section{Competing interests.}

All authors declare no conflicts of interest during the development of this study.

\section{Funding.}

Not applicable.

\section{Author Contributions:}

M.A.M., M.B., G.R.G., P.Z and M.A, conceived and designed the experiments. M.A.M., M.B. and G.R.G. performed the experiments. M.A.M, M.B., G.R.G., L.A. and B.C. analysed the data. M.A.M., M.B., G.R.G., B.C., P.T. and M.A.M., drafted the manuscript. All authors read, revised and approved the manuscript.

\section{Acknowledgements:}

This study was developed within the Center for the Development of Medical Education of the School of Medicine of the University of Sao Paulo (CEDEM- FMUSP). We thank Rosana dos Reis for her administrative support.

\section{Consent for publication:}

Not applicable.

\section{References}

1. WHO (COVID-19) Homepage. WHO Health Emergency Dashboard. Available from: https://covid19.who.int/

2. Rose S. Medical Student Education in the Time of COVID-19. JAMA. 2020. https://doi.org/10.1001/jama.2020.5227; 
3. Whelan A, Prescott J, Young G, Catanese VM. Interim guidance on medical students' participation in direct patient contact activities: principles and guidelines. Association of American Medical Colleges. Available from: https://lcme.org/wp-content/uploads/filebase/March-30-2020-Interim-Guidance-onMedical-Students-Participation-in-Direct-Patient-Contact-Activities.pdf. Access on March 30th, 2020;

4. Armocida B. et al. The Italian health system and the COVID-19 challenge. The Lancet. Vol 5 May 2020. Published Online March 25, 2020. DOI: https://doi.org/10.1016/S2468-2667(20)30074-8;

5. Legido-Quigley $\mathrm{H}$. et al. The resilience of the Spanish health system against the COVID-19 pandemic. The Lancet. Vol 5 May 2020. Published Online March 18, 2020. DOI: https://doi.org/10.1016/S24682667(20)30060-8;

6. Adams J.G., Walls R.M. Supporting the Health Care Workforce During the COVID-19 Global Epidemic. JAMA. 2020;323(15):1439-1440. doi:10.1001/jama.2020.3972;

7. Legido-Quigley $\mathrm{H}$. et al. Are high-performing health systems resilient against the COVID-19 epidemic? The Lancet. Vol 395 March 14, 2020. Published Online March 6, 2020. DOI: https://doi.org/10.1016/S0140-6736(20)30551-1;

8. Croda J. et al. COVID-19 in Brazil: advantages of a socialized unified health system and preparation to contain cases. Rev. Soc. Bras. Med. Trop. vol.53 Uberaba 2020 Epub Apr 17, 2020. http://dx.doi.org/10.1590/0037-8682-0167-2020;

9. Knobel, M. Cruesp divulga comunicado sobre suspensão das aulas a partir de 17/03. Jornal da USP. Campinas, [cited 2020 Mar 13]. Available from: https://jornal.usp.br/institucional/cruesp-divulgacomunicado-sobre-suspensao-das-aulas-nas-universidades-a-partir-de-17-03/;

10. Chinelatto, LA et al. What You Gain and What You Lose in COVID-19: Perception of Medical Students on their Education. CLINICS 2020;75:e2133. DOI: 10.6061/clinics/2020/e2133;

11. Corporation for National and Community Service, Office of Research and Policy Development. The Health Benefits of Volunteering: A Review of Recent Research, Washington, DC 2007;

12. Hustinx et al. Social and Cultural Origins of Motivations to Volunteer A Comparison of University Students in Six Countries. International Sociology. May 2010, Vol. 25(3): 349-382. DOI: $10.1177 / 0268580909360297$

13. Astin, Alexander W.; Sax, Linda J.; and Avalos, Juan, "Long-Term Effects of Volunteerism During the Undergraduate Years" (1999). Higher Education. Paper 88.

14. Goel $S$ et al. What motivates medical students to select medical studies: a systematic literature review. BMC Medical Education (2018) 18:16 DOI 10.1186/s12909-018-1123-4;

15. Stefan Tomas Güntert, Isabel Theresia Strubel, Elisabeth Kals \& Theo Wehner (2016) The quality of volunteers' motives: Integrating the functional approach and self-determination theory, The Journal of Social Psychology, 156:3, 310-327, DOI:10.1080/00224545.2015.1135864;

16. Frank JR, Snell L, Sherbino J, editors. CanMEDS 2015 Physician Competency Framework. Ottawa: Royal College of Physicians and Surgeons of Canada; 2015;

17. Jason R. Frank, Linda S. Snell, Olle Ten Cate, Eric S. Holmboe, Carol Carraccio, Susan R. Swing, Peter Harris, Nicholas J. Glasgow, Craig Campbell, Deepak Dath, Ronald M. Harden, William lobst, Donlin 
M. Long, Rani Mungroo, Denyse L. Richardson, Jonathan Sherbino, Ivan Silver, Sarah Taber, Martin Talbot \& Kenneth A. Harris (2010). Competency-based medical education: theory to practice, Medical Teacher, 32:8, 638-645, DOI: 10.3109/0142159X.2010.501190;

18. Brennan, T. et al. Medical Professionalism in the New Millennium: A Physician Charter. Annals of Internal Medicine. 2002. Volume 136. Number 3;

19. Frenk, J. et al. Health professionals for a new century: transforming education to strengthen health systems in an interdependent world. The Lancet. 2010. Vol 376;

20. Trad Leny A. Bomfim. Grupos focais: conceitos, procedimentos e reflexões baseadas em experiências com o uso da técnica em pesquisas de saúde. Physis. 2009: 777-796. https://doi.org/10.1590/S0103-73312009000300013.

21. Renée E. Stalmeijer, Nancy McNaughton \& Walther N. K. A. Van Mook (2014) Using focus groups in medical education research: AMEE Guide No. 91, Medical Teacher, 36:11, 923-939, DOI: 10.3109/0142159X.2014.917165

22. Baldassin S, Perotta B, Peleias M, Tempski P, Silveira PSP, Silva NR, et al. Relationship among Medical Student Resilience, Educational Environment and Quality of Life. PLoS One. 2015;:1-13;

23. Does my study require ethical approval? University of Cambridge, 2020. Available from: https://www.bio.cam.ac.uk/psyres/approval;

24. Denzin N, Lincoln YS: The Landscape of Qualitative Research: Theories and issues. 2ed. USA: Sage Publications Inc; 2003.

25. Patton MQ: Qualitative Evaluation and Research Methods. 2ed. London: SAGE Publications Inc; 1990.

26. Gerull $\mathrm{K}$ et al. Assessing gender bias in qualitative evaluations of surgical residents. The American Journal of Surgery 217 (2019) 306e313. DOI: https://doi.org/10.1016/j.amjsurg.2018.09.029;

27. Câmara, R. Análise de conteúdo: da teoria à prática em pesquisas sociais aplicadas às organizações. Revista Interinstitucional de Psicologia, 6 (2), jul - dez, 2013,179-191;

28. A. R. Mozzato, D. Grzybovski. Análise de Conteúdo como Técnica de Análise de Dados Qualitativos no Campo da Administração: Potencial e Desafios. RAC, Curitiba, v. 15, n. 4, pp. 731-747, Jul./Ago. 2011;

29. Nowell et al. Thematic Analysis: Striving to Meet the Trustworthiness Criteria. International Journal of Qualitative Methods Volume 16: 1-13, 2017. DOI: 10.1177/1609406917733847;

30. Caregnato RCA, Mutti R. PESQUISA QUALITATIVA: ANÁLISE DE DISCURSO VERSUS ANÁLISE DE CONTEÚDO. Texto Contexto Enferm, Florianópolis, 2006 Out-Dez; 15(4): 679-84;

31. Weaver R. et al. 'Part of the team': professional identity and social exclusivity in medical students. MEDICAL EDUCATION 2011; 45: 1220-1229;

32. Blakey et al. Are medical students socially exclusive? A comparison with economics students. Medical Education 2008: 42: 1088-1091doi:10.1111/j.1365-2923.2008.03126.x; 
33. Daniel Pagnin, Valéria De Queiroz, Márcio Amaral De Oliveira Filho, Naira Vanessa Anomal Gonzalez, Ana Emília Teófilo Salgado, Bernardo Cordeiro E Oliveira, Caio Silva Lodi \& Raquel Muniz Da Silva Melo (2013) Burnout and career choice motivation in medical students, Medical Teacher, 35:5, 388394, DOI: 10.3109/0142159X.2013.769673;

34. Hafferty, F.W. Beyond Curriculum Reform: Confronting Medicine's Hidden Curriculum. Academic Medicine. Vol. 73, n4. April 1998;

35. Mahase, E. Covid-19: medical students to be employed by NHS. BMJ 2020;368:m1156 doi: 10.1136/bmj.m1156 (Published 20 March 2020);

36. Gi, A. et al. Letter to the Editor: The Role of Medical Students in the COVID-19 Pandemic in Portugal. Ordem dos Médicos 2020. https://doi.org/10.20344/amp.13993;

37. Soled D et al. Medical Student Mobilization During A Crisis: Lessons From A COVID-19 Medical Student Response Team. Academic Medicine, 2020. DOI: 10.1097/ACM.0000000000003401 (manuscript ahead-of-print).

\section{Tables}

Table 1

Volunteers demographic distribution 


\begin{tabular}{|c|c|c|}
\hline Variables & & Amount of students* \\
\hline \multirow[t]{3}{*}{ Gender } & Female & $115(40 \%)$ \\
\hline & Male & $171(60 \%)$ \\
\hline & Other & $0(0,00 \%)$ \\
\hline \multirow[t]{3}{*}{ Year of medical programme } & 4th & $83(29 \%)$ \\
\hline & 5 th & $152(53 \%)$ \\
\hline & 6th & $51(18 \%)$ \\
\hline \multirow[t]{3}{*}{ Age group } & $20-22$ years old & $73(26 \%)$ \\
\hline & $23-25$ years old & $158(55 \%)$ \\
\hline & $\geq 26$ years old & $55(19 \%)$ \\
\hline \multirow[t]{2}{*}{ Risk group } & Yes & 3 \\
\hline & No & 283 \\
\hline \multirow[t]{5}{*}{ Transportation } & Public transport & $62(22 \%)$ \\
\hline & Private car & $103(36 \%)$ \\
\hline & App services & $7(2 \%)$ \\
\hline & Bike/Motorcycle & $2(1 \%)$ \\
\hline & Walking & $111(39 \%)$ \\
\hline
\end{tabular}

*Percentages were calculated according to the number of Volunteer Programme subscription form (286 students).

Table 2

Students distribution according to areas of interest

\begin{tabular}{lll} 
Areas of interest** & COVID-19 patients clinical assistance & $202(26 \%)$ \\
\cline { 2 - 2 } & Non-COVID-19 clinical assistance & $230(30 \%)$ \\
\hline Epidemiological surveillance & $102(13 \%)$ \\
\hline Clinical research & $102(13 \%)$ \\
\hline Support to online educational activities & $69(9 \%)$ \\
\hline Hospital administration & $74(9 \%)$
\end{tabular}

**Total percentage exceeded $100 \%$ because it was possible to choose more than one option in this section. 
Table 3

Qualitative data produced from the open-ended question: "What motivates you to volunteer during the COVID-19 pandemic?"

\section{Category Examples}

$\begin{array}{ll}\begin{array}{l}\text { Altruistic } \\ \text { reasons }\end{array} & \text { believe we are going through an unique and delicate moment of great difficulties. I } \\ \text { would like to help and try to minimize the impacts of the COVID-19 pandemic, } \\ \text { concerning patients and health care professionals. }\end{array}$

What motivates me is to help people who are going through great suffering. I would like to help my health care colleagues who are working and exposing themselves to take care of all the patients. I am willing to do whatever work is needed.

"I decided to volunteer for the same reasons that I have chosen the medical career. I am living far from my parents, who are from risk groups for COVID-19 infection, what makes me more available to help. I wish I could contribute to making health assistance as efficient as possible, fighting against the pandemic and diminishing the amount of work for health professionals. Regarding my limitations as a student, I am willing to help whenever it is necessary".

Duty I believe medical students have a great pledge to assist the population as future doctors, graduating at a public university. Right now all the support is welcome. I also volunteered as a way to confront the feeling of powerlessness I believe a lot of my colleagues are facing too.

I would like to help in the efforts against the pandemic and to put all the knowledge acquired during undergraduation into service for the population. I am also interested in Academic learning how to manage COVID-19 cases and how the health system is organizing in the interest midst of this unprecedented global shift.

As an intern, I believe I am able to help in some essential tasks during the pandemic. Moments like this are essential for our education as health professionals. Besides that, we're in a great public university and this volunteering opportunity would be a way of giving back all it has provided me.

I have great interest in Emergency Medicine and I intend to apply for residency in this area. Therefore, in the pandemic context, besides assisting patients, I could also learn more about this specialty. I believe the volunteers will help to unburden our health system and allow doctors to treat the patients with more time and quality whereas we help in minor tasks.

We are under a state of emergency - a pandemic with such proportions the world had not faced in a hundred years. I am proud of my University and Hospital for being an example for the rest of Brazil. I think the learning experience we can take out of it is huge. Medicine is the career I chose for my life and helping is a way of thanking all my colleagues currently working in the frontline against COVID-19.

Table 4

Qualitative data produced from the open-ended question about competencies 


\section{Category Examples}

Communicator

I believe that interpersonal relationships and communication skills are some of my strengths, so I could help in patient care. Furthermore, I am dedicated to learn and keep myself updated about the current situation. It might be of great help in screening and assisting patients. I also have experience in volunteering projects.

I am communicative, very easy-going and helpful. I wish I could participate in activities involving patient orientation about COVID-19 or assisting inpatients at wards (COVID-19 or not). I would really enjoy working in those areas.

Collaborator I am willing to work wherever I can be helpful! I am committed to learn any necessary skill and give all I can in order to help my colleagues and patients throughout this pandemic. One could say that I am a committed, organized and hardworking person. I am also willing to develop new competencies to help in any kind of volunteer activity.

Leader

Proactivity, organization, resilience. Proactivity: to propose, actively, quick and practical solutions to eventual difficulties. Organization: to manage working hours and projects with the academic curriculum of 6 th year. Resilience: to join efforts with a multiprofessional team in order to keep quality in patient care even in adverse times.

I believe that I am able to lead and organize people in a team, which might be useful in many contexts. I have worked in a research project during an exchange program for one semester and I have developed some ability in this field also. I have been class representative for many semesters and therefore I have learned a little about students' demands related to online education, which could be useful to volunteer activities. I am only in the 4th year, so although my medical abilities are limited I am very interested in medicine and a keen learner.

\section{Health advocate}

I really enjoy forming a relationship with patients. I am also a proactive person and I understand the relevance of every step in a workflow. Therefore, I am available to help in any task that involves patient care. I am a senior and I have already done the emergency rotations (cardiology, clinic, surgery and neurology), which gave me good theoretical and practical knowledge. Furthermore, I am totally motivated to help our hospital through this period. I have even left home and moved closer to the hospital in order to avoid infecting my beloved ones. I am at your service.

I have some knowledge from previous experience in non-COVID internships (Neonatology and Obstetrics) and a great interest in Internal Medicine and clinical reasoning, focused on treating COVID patients. I also have previous experience in scientific research (Harvard Exchange Program).

Since I was admitted to University, I have always enjoyed studying medicine. I believe that I have learned a lot during the last years in order to assist in patient care. On the other hand, I am really close to my grandmother, who is 91 years old, diabetic, hypertensive. Therefore, I would not like to work with COVID-19 + patients.

Before medical school, I studied for 2 and a half years of engineering. I feel very comfortable to deal with numbers and numeric systems. Thus, I think I would be of great value for the epidemiological surveillance volunteering program as I have great interest in charts and projections.

I am very interested in scientific discussions and I am currently keeping track of COVID-19 scientifical development. Therefore, I think I would be of great value in research projects also. 
Furthermore, I had an experience as a monitor of the Neurology discipline, which gave me the opportunity to learn using educational platforms. I have always had good grades, and, therefore, I think I have enough knowledge to help younger classes during online activities.

Professional I am very pragmatic and strict with safety guidelines and protocols. I obey orders and question them only in appropriate moments. I am very proactive and capable of taking quick decisions. I communicate well with patients from different age groups and look for having a broad vision of care.

Despite my lack of experience in some areas like epidemiology, management and laboratories, I don't mind helping in any of them. I am open to learning new things. I also have some experience with child care and medical education.

I am very helpful and committed to tasks when they are attributed to me. I am also very willing to learn new things and work in teams. I also believe that my attitude of taking things seriously and not panicking in face of negative outcomes, always helping my colleagues on their needs and challenges, are good characteristics to volunteer services.

\section{Table 5}

Data from focus group interviews: students' perceptions on management-related activities and leadership skills developed during the Volunteering Program and in medical training 


\begin{tabular}{|c|c|c|}
\hline Category & Issues & Examples \\
\hline \multirow[t]{7}{*}{$\begin{array}{l}\text { Activities } \\
\text { performed } \\
\text { as volunteers }\end{array}$} & $\begin{array}{l}\text { Healthcare- } \\
\text { related } \\
\text { activities }\end{array}$ & $\begin{array}{l}\text { "Many times, people who lived alone were scared, in the beginning } \\
\text { of the pandemic, (...) they didn't know how their disease would } \\
\text { progress (...) so, we called and we kept calling and sometimes } \\
\text { from one day to another we recognized the voices (...) it was } \\
\text { gratifying to do this follow up." }\end{array}$ \\
\hline & \multirow[t]{4}{*}{$\begin{array}{l}\text { Leadership } \\
\text { and } \\
\text { innovation }\end{array}$} & $\begin{array}{l}\text { "I thought that it was [an] enriching [experience] because we } \\
\text { worked with different people. Furthermore, we managed to work in } \\
\text { a group to organize that huge amount of data and try to come up } \\
\text { with some productive thing from that." }\end{array}$ \\
\hline & & $\begin{array}{l}\text { "I think [writing the institutional COVID-19 protocol] was something } \\
\text { very authoral, as it was our idea. [The supervisors] were just } \\
\text { guiding us. We had weekly meetings with them and some among } \\
\text { ourselves. With that we decided how to write. We were divided and } \\
\text { each one was writing a topic." }\end{array}$ \\
\hline & & $\begin{array}{l}\text { "What I found interesting was precisely [the fact] that neither we, } \\
\text { nor them, none of us knew how to write this document. So } \\
\text { everything was being built and [the supervisors] experience as } \\
\text { managers helped us a lot to see what would be feasible and } \\
\text { applicable in our reality." }\end{array}$ \\
\hline & & $\begin{array}{l}\text { "In fact, besides thinking about new ideas, we have adapted many } \\
\text { things to the reality of the University of São Paulo. Because } \\
\text { whether we wanted to or not, we discussed it a lot (...) And we } \\
\text { couldn't find almost anything in other documents. Because USP } \\
\text { has infinite realities. And we were in a big discussion: "How are we } \\
\text { going to do this? Are we going to list everything?" So I think it was } \\
\text { a great adaptation to our reality and it was really cool." }\end{array}$ \\
\hline & \multirow[t]{2}{*}{ Research } & $\begin{array}{l}\text { "It was a secure experience because we talked by phone, we } \\
\text { received the orientations, we were prepared (...) we could } \\
\text { communicate with people and learn from them how the } \\
\text { symptomatology presented (...) I think that in this aspect we } \\
\text { learned and discovered the disease." }\end{array}$ \\
\hline & & $\begin{array}{l}\text { "Firstly, we conducted research to develop the basis of the [USP } \\
\text { COVID-19] protocol (...) knowing the evidence about social } \\
\text { distancing, masks, PPIs, tests and trying to bring that to USP } \\
\text { reality (...)." }\end{array}$ \\
\hline \multirow{2}{*}{$\begin{array}{l}\text { Importance } \\
\text { of } \\
\text { management } \\
\text { and } \\
\text { leadership } \\
\text { skills as } \\
\text { curricular } \\
\text { components }\end{array}$} & \multirow[t]{2}{*}{$\begin{array}{l}\text { Private } \\
\text { practicing }\end{array}$} & $\begin{array}{l}\text { "(...) you will occasionally have some management position in } \\
\text { your private practice, in a hospital, in the health system, public, } \\
\text { private (...) even in the micro, if you have a small room as your } \\
\text { office, you already have to do some management of supplies, } \\
\text { human resources, logistics... and, in that sense, we have zero } \\
\text { knowledge." }\end{array}$ \\
\hline & & $\begin{array}{l}\text { "In a hospital, public or private, [having management skills] is very } \\
\text { important and it ends up that, in Brazil, these positions used to be } \\
\text { occupied by non-health professionals. However, we see that it is } \\
\text { starting to change recently, [as many doctors are starting to get } \\
\text { trained for this]. I really don't know if there is any medical school } \\
\text { that includes [management or leadership skills] in the curriculum, } \\
\text { but I think it is very necessary. And it is also important for private }\end{array}$ \\
\hline
\end{tabular}

Page 25/28 
practicing in the future. We leave college without knowing how to manage our own clinic."

Public-health "It is interesting to see in the macro view, you know? How the administration hospital was in that moment, we had a good dimension of how the hospital reduced in the worst time of the pandemic (...) it was very interesting to see from that point of view."

"In fact there should be room for [management and leadership] at graduation, especially in terms of public health. Because our university is public and we will work for most of our graduation - in fact, in full - at SUS."

Reflection on action

"I think that our teaching hospitals, for example, would be a good opportunity for including management in the undergraduate program.

We went through several crises, and are still going through some of them, in terms of hiring issues and lack of personnel, excessive demand, participation of private initiatives and so on. There are so many contradictions in terms of management and in terms of public health, but I feel that our teachers take very little responsibility for discussing this with us."

Motivation $\begin{aligned} & \text { Exploring new } \\ & \text { opportunities }\end{aligned}$

to volunteer
"I have chosen volunteering in management because I thought it could be an opportunity to learn something new that I would not learn during graduation. Although I felt unprepared by that time, I think it was a great experience."

"(...) At the beginning, I was afraid of the administrative field, so much that it was not my first option for volunteering. I have never felt capable, maybe because during graduation we do not have so much experiences like that. (...) Despite that, the volunteering program was a great opportunity to take the risk and overcome fear."

Altruistic reasons

"(...) The idea of contributing in some way to help in this moment of pandemic was of interest to me. As I was far away and that could be made (...) I wanted to help (...)"

"I believe that we, as future doctors, need to develop a sense of leadership and responsibility, and the fact that I study in a public university makes me feel like I have a moral obligation to return what was invested in me to society."

Academic interests
"I applied for almost every project at the Volunteering Program, because I did not want to stay at home during the pandemic. (...) I find it very difficult to learn by reading books or attending theoretical classes. I need to apply things. And that is the way I learn best."
Acquired skills from volunteering in management and leadership-
Resilience

"From the moment we jumped into this management thing, we learned to deal with the frustration of an uncontrolled environment, not controlled by ourselves or our team."

Collaborator

"(...) because we are used to only criticize the public administration and the way the things are done especially in critical situations that nobody has answers (...) so understand and live the 
related

activities limitations (...) made people sympathize with other that are in that position, being more comprehensive with the limitations (...)."

Communicator "I think that what I will carry with me, what most touched me in this voluntary process in the vigilance area was the importance of communication."

Professional "(...) (it) showed the necessity of organization, management of people, like the colleagues that were also participating in the vigilance (...) It was a great work that we did together, we felt what were the difficulties and built solutions to those challenges."

Scholar

"I think there was some technical learning involved, for example: I had never performed a review of literature before; and all the work of choosing and reading articles, to create a large group of references."

\section{Figures}

\section{MOTIVATION TO VOLUNTEER}

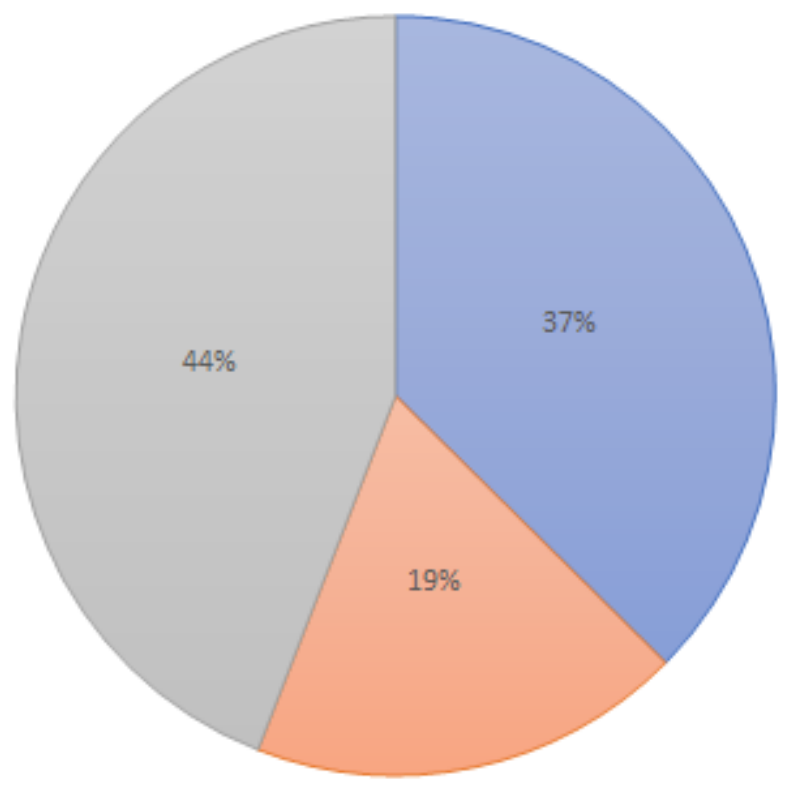

$\square$ DUTY $\square$ ACADEMIC INTEREST $\square$ ALTRUISTIC REASONS

\section{Figure 1}

Motivations to volunteer 


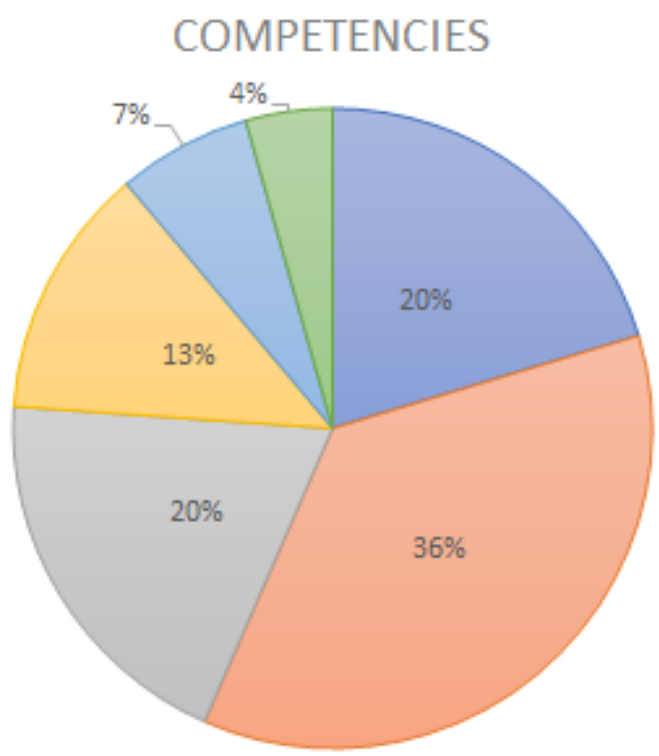

$\square$ COLLABORATOR $\square$ SCHOLAR $\square$ PROFESSIONAL $\square$ COMMUNICATOR $\square$ LEADER $\square$ HEALTH ADVOCATE

Figure 2

Medical students reported competencies according to CanMEDS 